\title{
Strengthening of steel-concrete composite girders using carbon fibre reinforced polymer (CFRP) plates
}

\author{
S M MOSAVI ${ }^{1, *}$ and A SADEGHI NIK ${ }^{2}$ \\ ${ }^{1}$ Department of Civil Engineering, Tonekabon Branch, Islamic Azad University, \\ Tonekabon, Iran \\ ${ }^{2}$ Young Researchers and Elite Club, Jouybar Branch, Islamic Azad University, \\ Jouybar, Iran \\ e-mail: dr.sayedmohammadmosavi@gmail.com
}

MS received 30 January 2014; revised 21 August 2014; accepted 22 August 2014

\begin{abstract}
Applying composites in order to strengthen and renew the infrastructures has globally been accepted. Traditional methods to strengthen the out-of-standard structures are costly, time consuming and requires a lot of labour. Today, new techniques are hired using light and strong substances which also resist against corrosion, known as Carbon Fibre Reinforced Polymer (CFRP) plates. Regarding the high tensile strength and proper module of elasticity, CFRP plates are considered as a suitable alternative to strengthen girders. The behaviour of steel-concrete composite girders being statically loaded and strengthened by CFRP plates in this study. The CFRP plates used in this study have been stuck, with epoxy adhesive, under the tensile sections of three steel girders. The results accompanied with analytical study of moment-curvature and numerical analysis done with ANSYS, show that CFRP plates with epoxy adhesive increases the ultimate loading capacity of steel-concrete composite girder. Plastic stiffness of the girders was also increased.
\end{abstract}

Keywords. Strengthening; CFRP; steel-concrete; ANSYS and composite.

\section{Introduction}

Today, Carbon Fibre Reinforced Polymer (CFRP) composite plates are widely being used to strengthen concrete structures. Distinctive physical specifications of such plates such as high tensile strength and module of elasticity have made them an excellent choice for strengthening. The tensile strength, for example, is over ten times as that of steel. Traditional strengthening methods include welding and using screws and dowels to attach steel plates. Steel structures require strengthening and restoration especially against environmental factors like corrosion. It is worth mentioning that using steel in structures like bridges should also be taken into consideration. For example, National Bridge Institute (NBI) has reported that $43 \%$ of the total bridges in the United

${ }^{*}$ For correspondence 
States are made of steel (FHWA 2001). These bridges have been strongly recommended to be restored and strengthened. Dissatisfactions of such bridges have mostly been reported because of getting rusty, improper maintenance and other damages due to fatigue. There are severed disadvantages in traditional strengthening methods of welding or doweling steel plates to other parts of the structures such as low durability (due to corrosion effects), suitable equipment for positioning the plates and over loading the structure (Klaiber et al 1987; Dorton \& Reel 1997). Furthermore, the structure might be sensitive to fatigue as a result of stress concentration due to welding or making holes for screwing or doweling.

Using Fibre Reinforcement Polymer (FRP) plates for strengthening and restoring concrete structures has scientifically been accepted and considerable researches have been done in this regard. Although using FRP composites have not yet been prevailed in order to strengthen steel structures, they have successfully been applied as patches in aviation and marine industry (Allan et al 1988; Grabovec et al 1993; Baker 1987). CFRP is the kind of FRP used in steel structures due to its high tensile strength and module of elasticity. Al-saidy (Al-Saidy et al 2007) tested six $3.05 \mathrm{~m}$ long steel composite beams. The beams were initially loaded in four-point static bending to yield the tension flanges after which they were strengthened using unidirectional CFRP plates. Strengthening can be achieved through the use of CFRP plates with strengthening up to $45 \%$ can be reached for the system investigated.

Schnerch (2005) showed that when applied on the outer layer, strips of CFRP increased the strength of steel structures. In one of the researches on strengthening cast-iron crossing beams, Rostasy showed that CFRPs could be used to strengthen them and that traditional analytical methods could be used in strengthening plans (Rostasy et al 2005). In another scientific study, two corroded beams of a bridge were restored by strips of CFRP on the top and bottom tensile sections (Mertz \& Gillespie 1996). Before restoration, elastic stiffness of the two beams was $20 \%$ and 32\% lower than that of new ones, but after applying CFRP it reached to upto $83 \%$ and $97 \%$, respectively. Liu conducted an experiment with four I-shaped beams, each 2.44 meters long (Liu et al 2001). He first cut $100 \mathrm{~mm}$ of the tensile section along three beams in order to simulate the condition of corrosion and then restored it with CFRP. For the last beam he strengthened one-fourth of the total length. Load bearing of the three beams was increased by $56 \%$ and for the last beam $41 \%$. Patnaik and Buer experimented three beams by 4-point loading test two of which were completely restored by CFRP along the length. They reported $14 \%$ of increase in plastic moment for the two beams (Patnaik \& Buer 2004). Sen also loaded, in 4-point loading test, other steel-concrete composite beams up to yielding point and then restored them by CFRP and reported a considerable increase in yielding strength and ultimate loading capacity of the beams (Sen \& Libby 1994). Using 1, 3 and 5 layers of CFRP, remained deflection due to loading is decreased and load bearing capacity will be 44, 51 and 76 percent, respectively. The higher the CFRP's module of elasticity, the more will be load bearing capacity. Another experiment conducted on three steel-concrete composite girders in Arizona University (Tavakkolizadeh \& Saadatmanesh 2003c). These were steel W355*45 girders compounded with a concrete 910 $\mathrm{mm} * 75 \mathrm{~mm}$ slab strengthened with one, three and five $76 \mathrm{~mm} * 1.27 \mathrm{~mm}$ CFRP strips. They were loaded at four points $500 \mathrm{~mm}$ away from each other and the span was $4.78 \mathrm{~m}$ which resulted in higher plastic strength and stiffness in the girders. The usage of CFRP strips decreases the rate of crack development on the concrete slab over the steel profile (Tavakkolizadeh \& Saadatmanesh 2003a). Another study on three steel-concrete composite girders with the same dimensions has been done making slots with $1.27 \mathrm{~mm}$ wide and different lengths on the tensile section; one with $25 \%$, the other with $50 \%$ and the last one $100 \%$ onto the cross section (Tavakkolizadeh $\&$ Saadatmanesh 2003b). Then these girders were strengthened with one, three and five CFRP plates. The elastic and post-elastic stiffness were recovered by 86 to 102 and 32 percent. Other 
researches have also shown that CFRP plates have had a great impact on increasing the capacity of load bearing in girders.

\section{Experimental investigation}

\subsection{Description of specimens}

There were a total of 5 steel-concrete composite girders studied in this research. They were 1.8 $\mathrm{m}$ long, made of IPE14 profiles. A concrete slab, $450 \mathrm{~mm}$ wide and $65 \mathrm{~mm}$ thick was put on the length of girders. U-shaped shearing studs were used to attach the slab and the girder. Three of the girders were strengthened with CFRP plates and the other two without them. The sketch of the test beam is shown in figure 1 .

\subsection{Epoxy materials}

Two-component viscose epoxy was used to attach CFRP plates to the beam. Mixing ratio was as one part resin and three parts hardener in volume. The epoxy was then kept in room temperature at $23^{\circ} \mathrm{C}$ for 7 days.

\subsection{CFRP}

Carbon Fibre Reinforced Polymer plate, $70 \mathrm{~mm}$ wide and $1.4 \mathrm{~mm}$ thick was used for the experiment. Its average tensile strength was $3700 \mathrm{Mpa}$ and its tensile module of elasticity was $200 \mathrm{Gpa}$ with a Poisson's coefficient of 0.34 .

\subsection{Steel}

A hot-rolled steel profile of IPE14 was used in the experiment. Single-axis tensile test was conducted on four samples of $125 \mathrm{~mm}$ long, $25 \mathrm{~mm}$ wide and $6.7 \mathrm{~mm}$ thick cut from the profile. Tensile strength, module of elasticity and Poisson's coefficient were $240 \mathrm{Mpa}, 200 \mathrm{Gpa}$ and 0.3 , respectively. The stress-strain diagram is shown in figure $2 \mathrm{a}$. The concrete slab was reinforced by $120 \mathrm{~mm} * 120 \mathrm{~mm}$ mesh of $\Phi 12$ rods to resist against temperature changes and shrinkage.

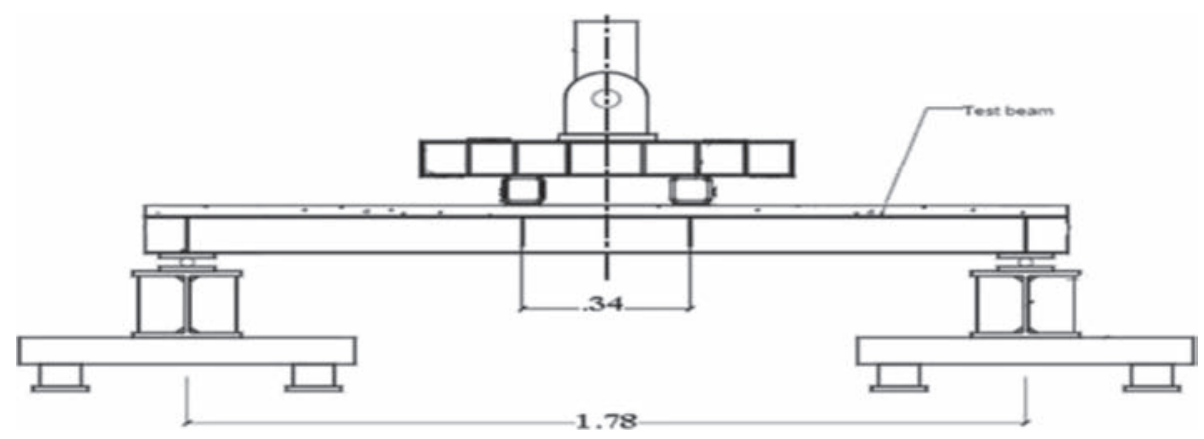

Figure 1. Test beam diagram. 


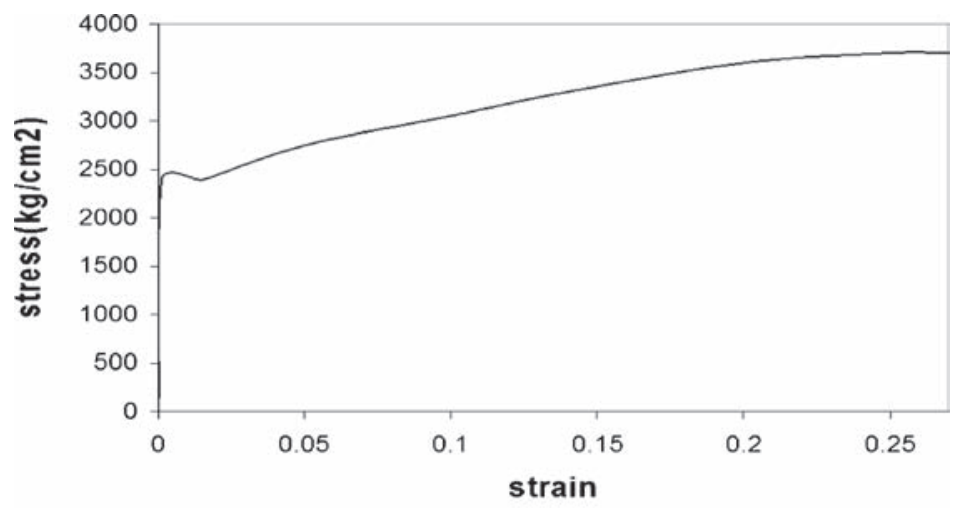

(a)

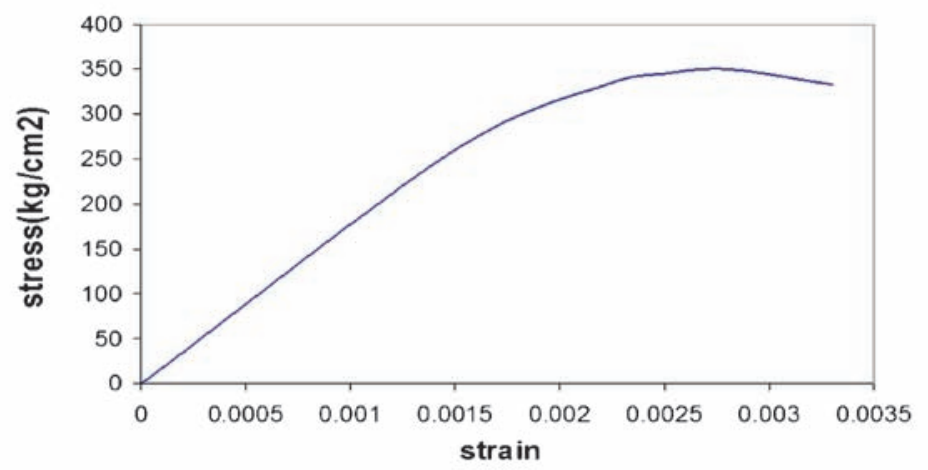

(b)

Figure 2. Stress-strain diagram for (a) concrete, (b) steel.

\subsection{Concrete}

The slab was made of a concrete with $35 \mathrm{Mpa}$ strength, $100 \mathrm{~mm}$ slump and maximum aggregate size of $10 \mathrm{~mm}$. four cylindrical $150 \mathrm{~mm} * 300 \mathrm{~mm}$ samples were made and protected. 28-day compression strength was measured as $35 \mathrm{Mpa}$ and module of elasticity was $20 \mathrm{Gpa}$. The stressstrain diagram of the concrete for single-axis compression test is shown in figure $2 \mathrm{~b}$.

\section{Sample and experimental equipment preparation}

The steel beams have been cut in pieces each $1.9 \mathrm{~m}$ long. Then stiffeners were set on compression section of the beams in a row with a center-to-center span of $100 \mathrm{~mm}$. After that a mesh of rods was put in a distance of $30 \mathrm{~mm}$ from the compression section of the beam. Finally, the concrete slab was put on the unit. At the same time cylindrical concrete samples were made to be used in single-axis compression test. These samples being covered by a plastic sheet were kept in a humid area for 28 days. Details are presented in figure 3.

CFRP plates were cut in certain length of $1.5 \mathrm{~m}$ and $70 \mathrm{~mm}$ wide. The ending edge of the plates was softened by soft sandpaper No.150. The surface of the steel was also smoothened 


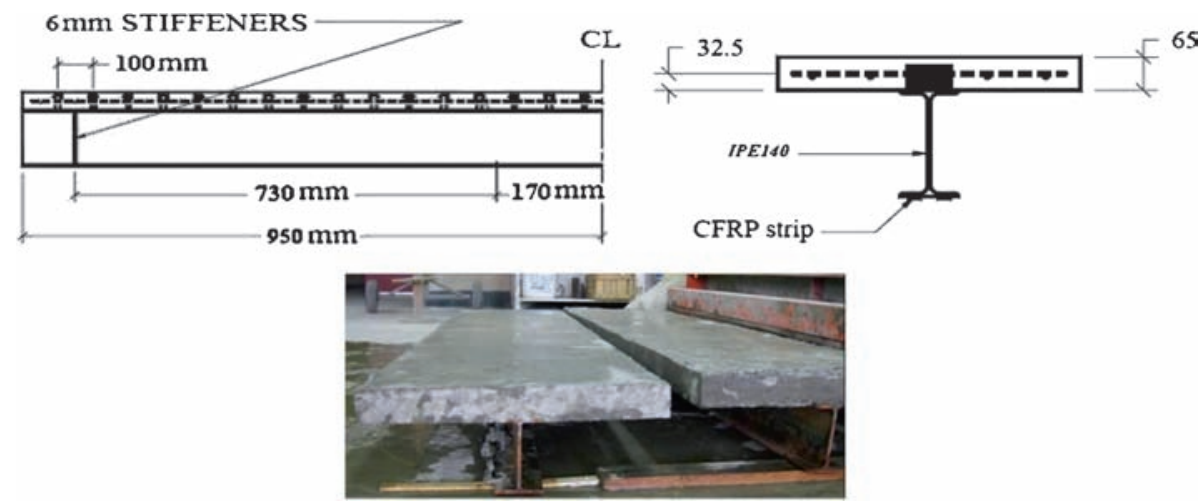

Figure 3. Illustration of the beam and cross section.

by sandblast and then washed by methanol. Turning the ending edges over to $45^{\circ}$ decreases the shearing stress on the shared surface between steel and CFRP plate and also in the adhesive (Schnerch 2005). Miller showed that the least length needed to shift the entire force from steel to CFRP plate was $100 \mathrm{~mm}$ (Miller et al 2001). On the other hand, the proposed angle by Schnerch was $20^{\circ}$, therefore in this research ending angle was also $20^{\circ}$ as shown in figure 4 .

Adhesive was put on the dried surface of the beam; then CFRP plate was put on the adhesive and pressed slightly to let the bubbles out. Then strain gages were set on the surface of the steel, CFRP plate and slab. In order to avoid lateral moment, some lateral fixtures were used. Strain in different sections of the beam was measured. This was done to study the behaviour in different sections where shearing stress between the adhesive and plate were measured. Strain was measured by transducer in order to locate the middle point of the span. To measure the strain in different points whether cross sections or along the span, a micro-strain meter was used.

\section{Analytical method}

Moment-curvature method has been used by Mattock for prestressed concrete beams (Mattock 1979). Since this is a good method for prediction the behaviour of pre-stressed concrete, it could be a proper way to assess the composite behaviour of steel-concrete (Collins \& Mitchell 1997). Therefore, it is also suitable for assessing the behaviour of steel-concrete composite strengthened by CFRP plates. The analytical curve is obtained based on moment-curvature relation for the cross section and deflection of the middle span.

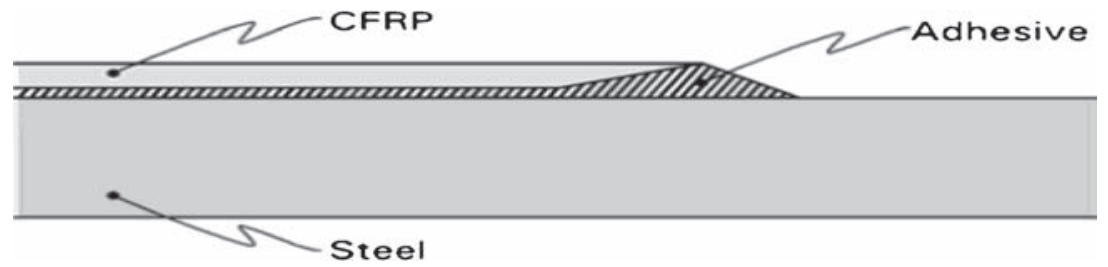

Figure 4. Attachment of the ending edge of CFRP plate to steel beam by adhesive. 
Defining the moment-curvature relation is based on the following assumptions:

(i) Strain distribution and variation along the section is linear.

(ii) Adherence between CFRP plate and steel and between concrete and steel is perfect.

(iii) Stress-strain relation for elastic steel is perfect plastic.

(iv) Stress-strain relation for CFRP plate is linear.

(v) Stress distribution in concrete is based on the proposed relation by Collins \& Mitchell (1997).

Cross section of the beam should be divided into thin layers in order to define momentcurvature relation. Strain in concrete first reaches to 0.002 on top before it reaches to ultimate strain at 0.0032 . For each stage of strain increase, neutral axis depth is defined by trial and error so that the section will come to equilibrium. Then the moment as a result of forces in section is defined around neutral axis. The amount of curvature is defined by dividing concrete strain by neutral axis depth. $\left(\varphi=\frac{\varepsilon c}{C}\right)$. This process continues until either concrete reaches to its ultimate strain or CFRP plate to its yielding strain. The latter point in strain-curvature curve is defined as the curvature capacity of the section and ultimate yielding force according to curvature capacity of the section. The amounts of stress and strain in the section are shown in figure 5. Once the strain-curvature diagram is obtained, force-deflection relation will be defined through Moment Area Theory method. The beam is divided into 50 sections. Using Virtual Work Principle, the deflection of the middle span will be obtained by the following relation:

$$
\delta=\int_{0}^{L} \varphi(x) m(x) d x,
$$

where $\varnothing(\mathrm{x})$ and $\mathrm{m}(\mathrm{x})$ are the real curvature and virtual moment, respectively.

\section{Numerical modelling}

In this research, Finite Element model with ANSYS code is used to assess the stresses in the reinforced beam with CFRP plates. In this model, Solid 45 element and Solid 65 elements are used for steel beam and concrete, respectively.

These are three-dimensional elements but Solid 65 is capable for exertion tensile and compression cracks. Solid64 element is used for modelling CFRP plates with epoxy adhesive and

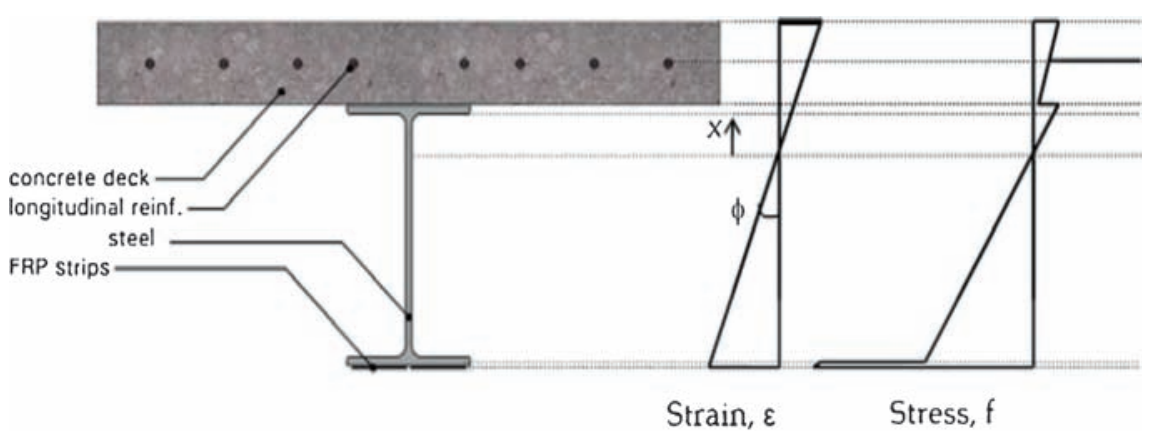

Figure 5. Strain variation at the elevation of the section. 
Link8 element is used for modelling the rods in concrete slab. The elements are shown in figure 4 . These are 8-node elements. Each node has three degrees of freedom along X, Y and $\mathrm{Z}$ axis. In order to calculate the element stiffness, $2 * 2 * 2$ Gauss integration plan is used. In elastic stage concrete is assumed to be isotropic material. ANSYS elements and the mesh are shown in figure 6. Force is exerted stage by stage using Newton-Raphson method. Regarding the behaviour, Multi Linear Isotropic for steel and the relation introduced by Desayi \& Kreishna (1964) and also Gere \& Timoshenko (1997) for concrete are considered (Desayi \& Kreishna 1964; Gere \& Timoshenko 1997). For rods, two-line behaviour and for CFRP, linear behaviour is considered.

Attaching method for CFRP and steel profile and also concrete element attachment and steel rod are shown in figure 7.
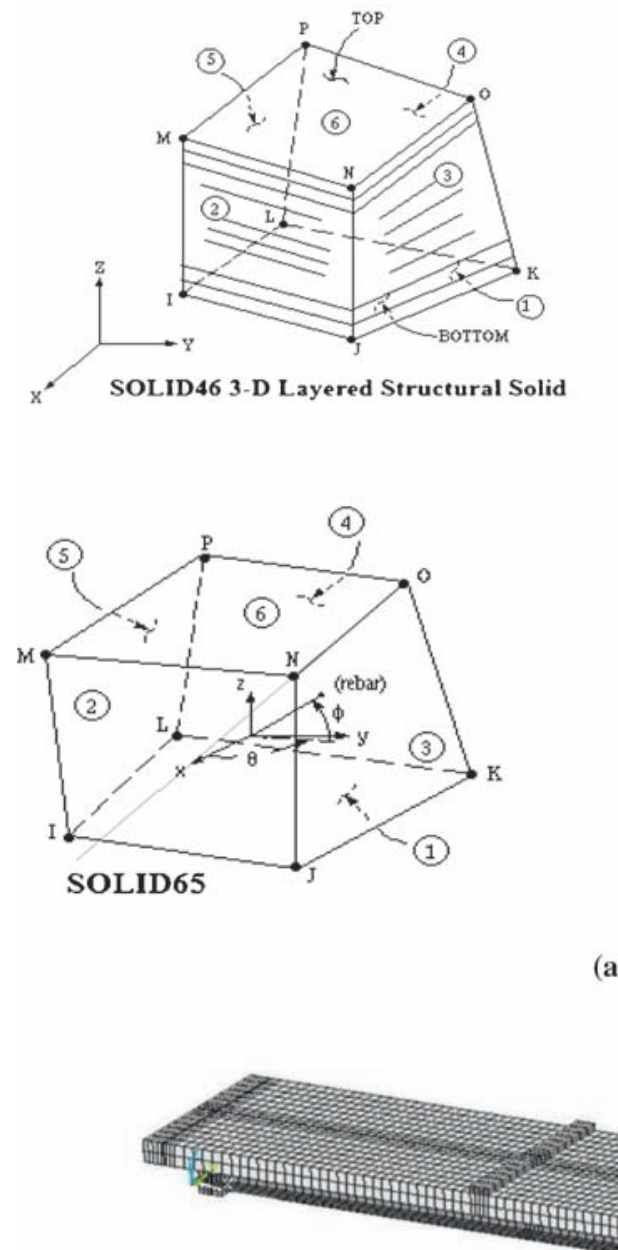

(a)

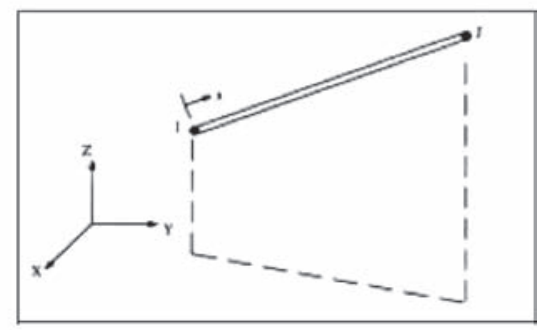

Link8

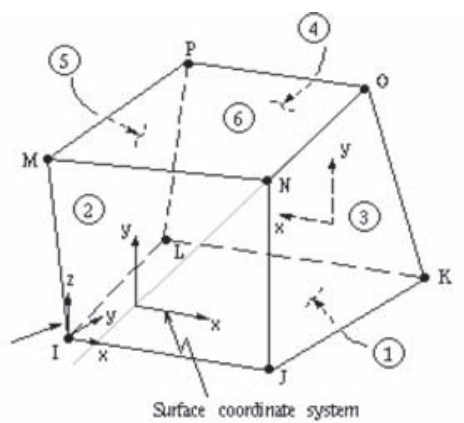

SOLID45 3-D Structural Solid

\section{RNSYS}

(b)

Figure 6. (a) Elements used in beams. (b) Beam and the elements for composite beam. 


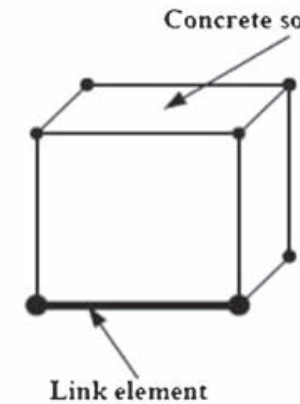

(a)

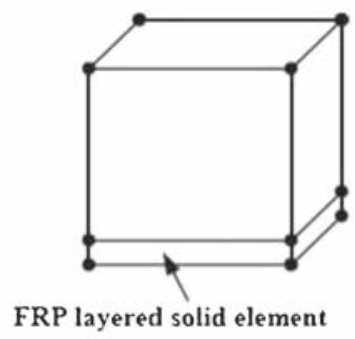

(b)

Figure 7. Attachment of CFRP plate to steel beams and concrete element to steel rods.

Regarding that concrete is considered as a fragile material, its tensile and compressive behaviours are different. Its tensile strength is about 8-15 percent of its compressive strength (Bangash 1989). Concrete's stress-strain behaviour is linear at $30 \%$ of maximum compressive strength and after that, the behaviour is nonlinear. Concrete's module of elasticity and its Poisson's coefficient are considered to be $20 \mathrm{Gpa}$ and 0.2, respectively (Bangash 1989). $\mathrm{F}_{\mathrm{r}}$ according to ACI (1996) is defined as follows:

$$
f_{r}=7.5 \sqrt{f_{c}^{\prime}}
$$

where $f_{c}^{\prime}$ and $f_{r}$ are in Psi.

Relations (3), (4) (Desayi \& Kreishna 1964) and (5) (Gere \& Timoshenko 1997) are used for nonlinear behaviour of concrete:

$$
\begin{gathered}
f=\frac{E_{c} \varepsilon}{1+\left(\frac{\varepsilon}{\varepsilon_{0}}\right)^{2}} \\
\varepsilon_{0}=\frac{2 f_{c}^{\prime}}{E_{c}} \\
E_{c}=\frac{f}{\varepsilon} .
\end{gathered}
$$

For the case of steel profile, Multi-linear Isotropic (MISO) is used in ANSYS program and for steel rods, two-line behaviour is us used.

\section{Test results and discussion}

Load-deflection diagrams for the middle of the span in control beams are shown in figures 8 and 9. As mentioned, two of the beams were as control ones to evaluate the behaviour of three beams strengthened by CFRP plates. The behaviour of the control beams was first linear and then nonlinear and finally following the disruption of concrete they also disrupt. Concrete slab protects the steel beam laterally against lateral moment. Also used stiffeners cause a composite behaviour through the entire beam. They also prevent any local moment. As shown in figure 8 the force needed to disrupt the steel beam after the disruption of concrete is 11.8 tons. Figure 9 shows force-deflection diagram for the steel-concrete composite beams strengthened with CFRP 


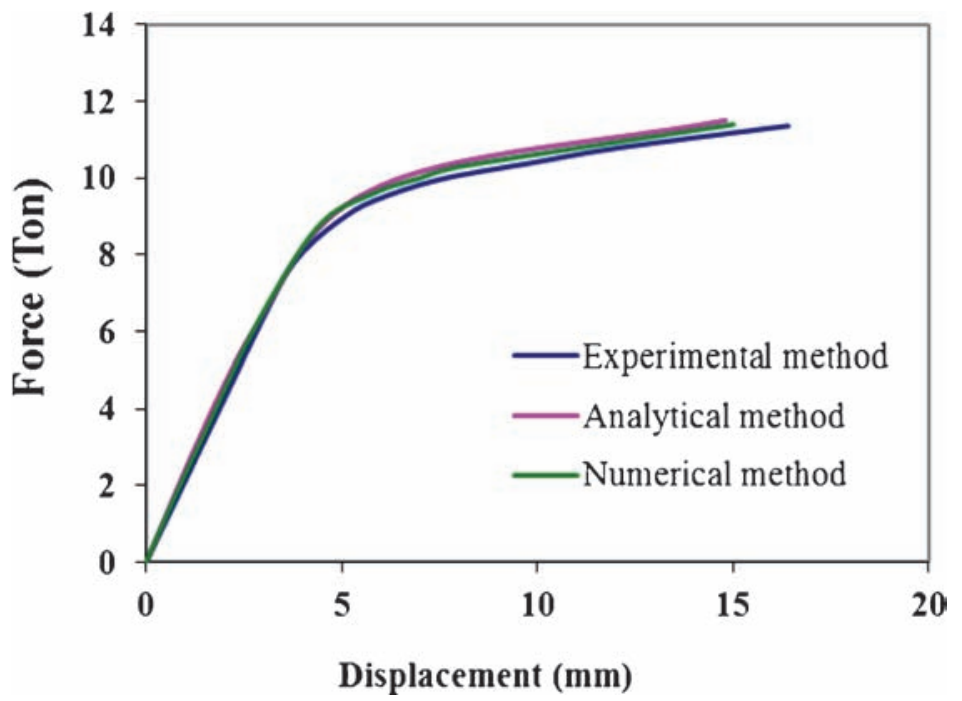

Figure 8. Load vs. deflection of tested control beam.

plates. There is a good agreement between analytical and experimental results. At the beginning of the experiment, there was a nonlinear behaviour observed as cracks due to shrinkage. For example, for the beams not strengthened, at 3.12 tons the cracks were completely disappeared and the behaviour changed to linear. Figure 8 shows an almost linear behaviour for the beams not strengthened up to 8.4 tons and then it changed to nonlinear. When the force reaches to 9 tons, longitudinal cracks were seen along the compressive section. As the force grows, the cracks occur more so hiring rods is suggested to avoid more cracks. On the other hand, CFRP plates

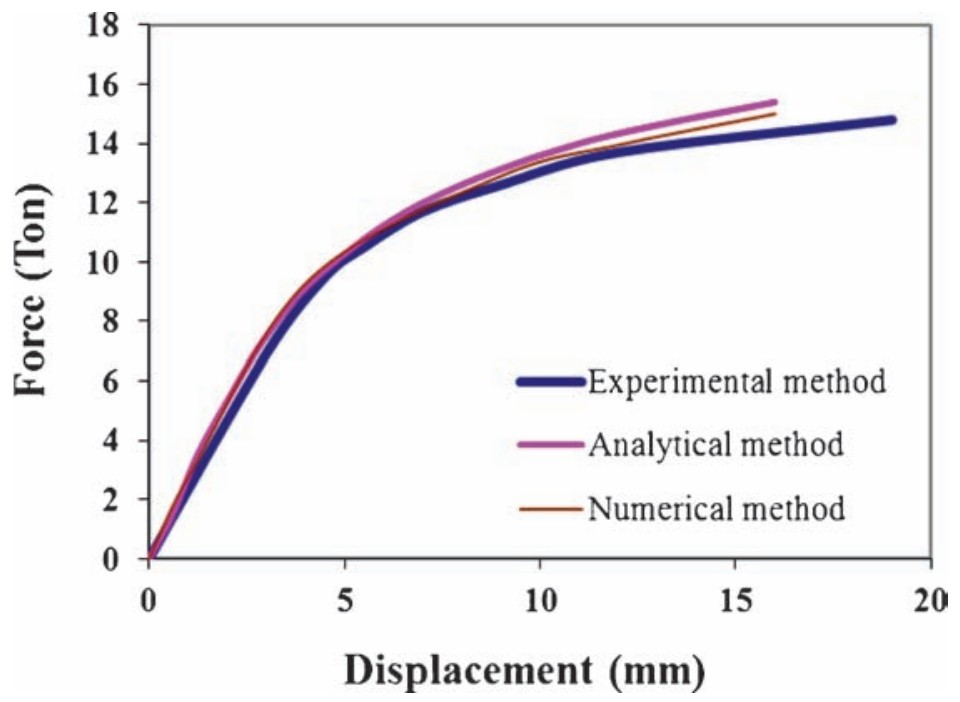

Figure 9. Load vs. deflection of tested strengthened beam. 


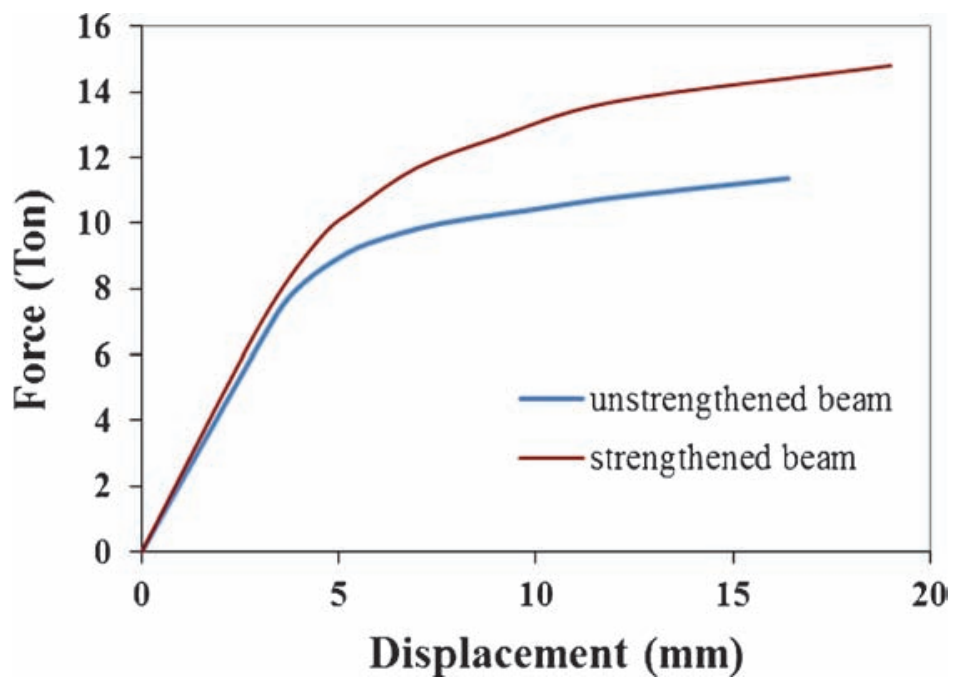

Figure 10. Comparison of mid-span deflection in experimental study.

stuck under tensile section, have an elastic linear behaviour and regarding more loading, they bear more force before tensile section reaches to yielding point.

Ultimate deflection in control composite beams is about $23 \mathrm{~mm}$ while for the strengthened ones deflection in the middle of the span reaches to $12 \mathrm{~mm}$. Figure 10 shows the different deflection of the middle of the span in strengthened and control beams.

Control beams disrupt at 11.8 tons while in strengthened ones disruption occurs at 14.8 tons that is $26 \%$ increase in bending strength. Strengthened beams reach the disruption a little earlier due to a slight creep on the surface of concrete and steel.

As mentioned before, desired results are achieved assuming a perfect adherence between concrete and steel, steel and CFRP plate. Hence the force required for disruption is slightly less than expected. On the other hand, as CFRP plates are thin, there will not be much changes expected. In strengthened beam, nonlinear behaviour begins when a load of 9.6 tons is applied which is more compared to control beams in which it begins when a load of 8.4 tons is applied. Deflection in strengthened beam is $6 \mathrm{~mm}$ while in control beam it is $10 \mathrm{~mm}$. A considerable increase in stiffness is observed during the post-elastic stage in strengthened beam. In these experiments, the disruption of the beams were due to the disruption of CFRP plates and concrete slab. The cracks in concrete slab are shown in figure 11.

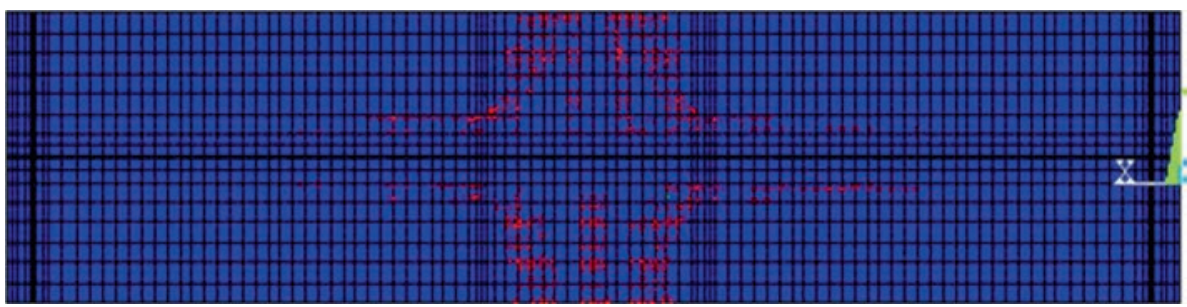

Figure 11. The cracks in slab by numerical method (ANSYS). 


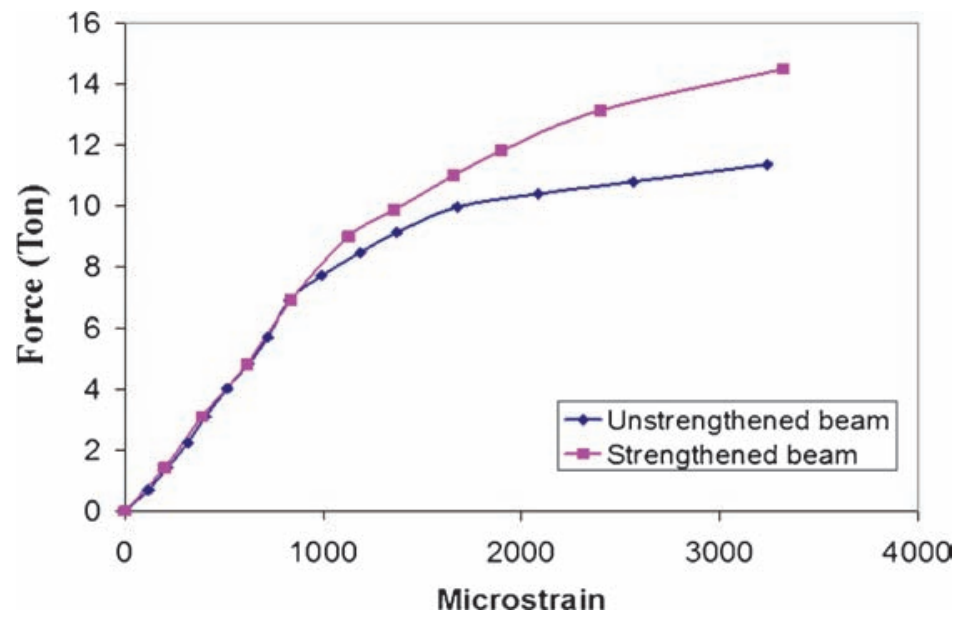

Figure 12. The mid-span strain on top of the concrete beam.

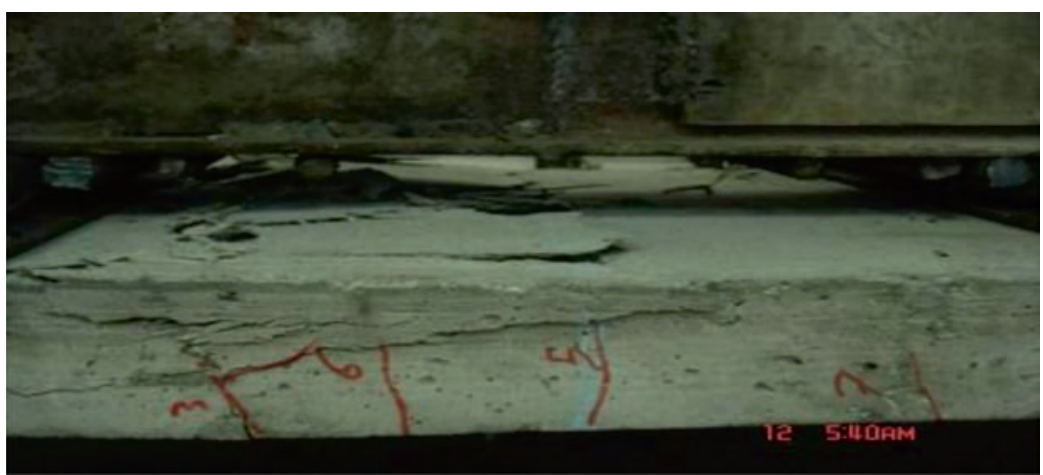

Figure 13. Disruption of concrete slab.

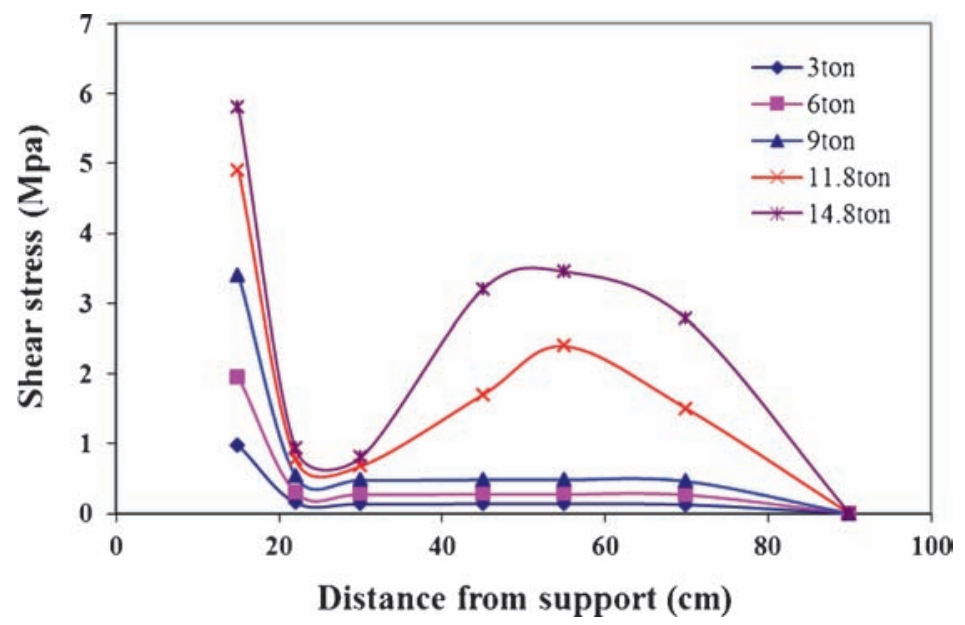

Figure 14. Shear stresses in epoxy. 
Strain in the middle of the span on concrete slab in strengthened and control beams are shown in figure 12 .

Maximum strain of concrete was 0.0032. Compressive disruption is shown in figure 13 at which most of the samples were disrupted.

Effectiveness of strengthening method lies considerably on the attachment of steel and CFRP plate. To observe the shearing stress distribution along CFRP plate in epoxy adhesive numerical analysis and ANSYS software are used. Shearing stress is shown in figure 14. Maximum shearing stress occurs at the end of CFRP plate. Also, when plastic behaviour begins, there is a considerable increase in shearing stress which occurs at 1/3 away from the middle of the span.

\section{Conclusions}

Following conclusions are drawn from the results.

- Using CFRP plate increases the bearing capacity of the composite beam so in the beam tested bearing capacity was observed up to an ultimate capacity $26 \%$.

- Stiffness of the beam was considerably increased at plastic stage which was about $25 \%$.

- Flexibility of the strengthened beam with CFRP plates was slightly decreased.

- Numerical and analytical results obtained are in agreement with the previously reported results.

\section{References}

Allan R C, Brid J and Clarke J D 1988 Use of adhesives in repair of cracks in ship structures. Mater. Sci. Technol. 4: 853-859

Al-Saidy A H, Klaiber F W and Wipf T J 2007 Strengthening of steel-concrete composite girders using carbon fiber reinforced polymer plates. Construction Build. Mater. 21: 295-302

Baker A A 1987 Fiber composite repair of cracked metallic aircraft components of particial basic aspect. Composites 18(4): 293-308

Bangash M Y H 1989 Concrete and concrete structures: Numerical modeling and application. London, England: Elsevier Science Publisher Ltd

Collins Michael P and Denis Mitchell 1997 Prestressed concrete structures. Canada: Response Publication

Desayi P and Kreishna S 1964 Equation for the stress-strain curve of concrete. J. Am. Concrete Inst. 61: 345-350

Dorton R A and Reel R 1997 Methods for increasing live load capacity of existing highway bridges. NCHRP Synthesis 249, TRB, National Research Council, Washington, DC; 66

FHWA Bridge program Group 2001 Count of deficient highway bridges. The office of bridge technology, the federal highway administration. Washington: D.C.

Grabovac I, Bartholomeusz R A and Baker A A 1993 Composite reinforcement of ship superstructureproject overview. Composites 24(6): 501-509

Gere J M and Timoshenko S P 1997 Mechanics of materials. Boston, Massachusetts: PWS Publishing Company

Klaiber F W, Dunker K F, Wipf T J and Sanders W W 1987 Method of strengthening existing high-way bridges. NCHRP Report No.293, TRB, National Research Council, Washington, DC; 114

Liu X, Silva P and Nanni A 2001 Rehanilitation of steel bridge members with FRP composites materials. Figueiras, J., Javanese, L. and Furia, R. (eds), In: Proceedings of CCC 2001, Composites in construction, 613-617

Mattock Alan H 1979 Flexural strength of prestressed concrete sections by programmable calculator. PCI Journal 24: 32-54 
Mertz D R and Gillespie J W 1996 Rehabilitation of steel bridge girders through the application of advanced composite materials (Contract NCHRP-93-ID011). Transportation Research Board. Washington, D.C.

Miller T C, Chajes M J, Mertz D R and Hastings J N 2001 Strengthening of a steel bridge girder using CFRP plates. J. Bridge Eng. 6(16): 514-522

Patnaik A K and Buer C L 2004 Strengthening of steel beams with carbon CFRP laminates. In: 4th international conference on advanced composite materials in bridges and structures, Calgary, 1-8

Rostasy F S, Neubauer U and Nothnagel R 2005 Strengthening of historic cast iron girder with bonded CFRP plates. Seracino (ed.), In: FRP composites in civil engineering- CICE 2004, Leiden, A.A. Belkama, 725-731

Sen R and Libby L 1994 Repair of steel composite bridge section using CFRP laminates. Final report submitted to Florida and us department of transportation, Virginia: NTIS

Schnerch D 2005 Strengthening of structures with high modulus carbon fiber reinforced polymer (CFRP) materials. Ph.D. dissertation, North Carolina state University, Raleigh, North Carolina

Tavakkolizadeh M and Saadatmanesh H 2003a Fatigue strength of steel girders reinforced with carbon fiber reinforced polymer patch. J. Struct. Eng. 129(2): 186-196.

Tavakkolizadeh M and Saadatmanesh H 2003b Repair of damaged steel-concrete composite girders using carbon fiber reinforced polymer sheets. J. Composites Construction. 7(4): 311-322

Tavakkolizadeh M and Saadatmanesh H 2003c Strengthening of steel-concrete composite girder using carbon fiber reinforced polymer sheets. J. Struct. Eng. 129(1): 30-40 